\title{
SATISFACTION WITH COGNITIVE REHABILITATION DELIVERED VIA THE INTERNET IN PERSONS WITH ACQUIRED BRAIN INJURY
}

\author{
THOMAS F. BERGQUIST, PHD ${ }^{1,2}$, MAYA YUTSIS, PHD ${ }^{3}$, MOLLY J. SULLAN, BS ${ }^{4}$
}

${ }^{1}$ DEPARTMENT OF PSYCHIATRY \& PSYCHOLOGY, MAYO CLINIC COLLEGE OF MEDICINE, ROCHESTER, MN, USA ${ }^{2}$ DEPARTMENT OF PHYSICAL MEDICINE \& REHABILITATION, MAYO CLINIC COLLEGE OF MEDICINE, ROCHESTER, MN, USA

${ }^{3}$ DEPARTMENT OF PSYCHOLOGY, VA PALO ALTO HEALTHCARE SYSTEM, PALO ALTO, CA, USA

${ }^{4}$ DEPARTMENT OF CLINICAL AND HEALTH PSYCHOLOGY UNIVERSITY OF FLORIDA, GAINESVILLE, FL, USA

\section{ABSTRACT}

We examined the level of satisfaction with cognitive rehabilitation delivered via the Internet in persons with moderate to severe acquired brain injury $(\mathrm{ABI})$. Fifteen adults with moderate to severe $\mathrm{ABI}$ were randomized to 30 days of Internetbased active treatment (AT) or to a wait list (WL) group, and crossed over to the opposite condition after 30 sessions. Both caregivers and participants were assessed at three time points during the study. This study focused on participant satisfaction with receiving treatment in this manner. Though the results of this study showed no significant treatment effect, the vast majority of participants (>87\%) were satisfied with treatment. Treatment satisfaction accounted for $25 \%$ of additional variance in predicting lower family ratings of mood difficulties after final assessment $(p<.03)$. Greater satisfaction with treatment was positively correlated with greater employment rate after treatment $(r=.63, p=.02)$, as well as lower family ratings of memory and mood difficulties after final assessment $(r=-.59, p=.03 ; r=-.58, p=.03$, $)$. Results suggest that treatment satisfaction in persons with $\mathrm{ABI}$ is related to less activity limitations, and maintaining employment after cognitive rehabilitation delivered via the Internet.

Keywords: Acquired brain injury, telerehabilitation, treatment satisfaction

Traumatic brain injury (TBI) is a highly prevalent health concern in the United States, with an estimated 1.7 million people sustaining a TBI each year (Faul, Xu, Wald, \& Coronado, 2010). The impact of such an injury can cause lifelong impairment, including occupational restrictions, as well as cognitive, behavioral and emotional sequelae (Ponsford et al., 2014). Many people suffering from TBI live in remote areas, and often have poor access to necessary rehabilitative services on a regular, longer-term basis (Johnstone, Nossaman, Schopp, Holmquist, \& Rupright, 2002).

To address this problem, telerehabilitation - a service delivery model that uses computer-based services to provide assistance to patients in remote areas - has increasingly been implemented by medical facilities. Telerehabilitation has shown promising results in both improved outcomes and patient satisfaction with treatment (Schopp, Johnstone, \& Merveille, 2000). Importantly, Internet use in disabled populations is also on the rise, making this model more accessible (Vaccaro, Hart, Whyte, \& Buchhofer, 2007). Separate studies by Vaccaro et al., Egan et al., and Goodman et al. show that disabled populations with access to a computer use the Internet frequently (5-7 times per week), and that those with no access to a computer strongly desire to go online (Egan, Worrall, \& Oxenham, 2005; Goodman, Jette, Houlihan, \& Williams, 2008; Vaccaro et al., 2007). 
In earlier research, we examined the effect of Internetbased cognitive rehabilitation in persons with severe TBI, and found significant improvements in the use of compensatory strategies and on family reports of improved mood and memory following treatment (Bergquist et al., 2009). We then examined the effect of active treatment (i.e., calendar use acquisition training) on Independent Living Scale (ILS) ratings, which were tested via the same instant messaging model (Forducey, Glueckauf, Bergquist, Maheu, \& Yutsis, 2012). The ILS was dichotomized as dependent (i.e., requiring some supervision) versus independent (i.e., fully independent/no supervision required) and was examined as a primary outcome variable (Forducey et al., 2012). After the active treatment condition, $86 \%$ of participants were rated as independent, as opposed to only $64 \%$ after the wait list condition (Forducey et al., 2012). These results, along with findings from our previous studies, have provided preliminary support that Instant Messaging (IM) based telerehabilitation is associated with higher levels of independence (Bergquist, Gehl, Lepore, Holzworth, \& Beaulieu, 2008; Bergquist et al., 2009; Bergquist, Thompson, Gehl, \& Munoz Pineda, 2010; Forducey et al., 2012).

Satisfaction with treatment is also an important part of the rehabilitation process, and many studies have found that higher rates of satisfaction can predict higher compliance with treatment recommendations outside of the therapy setting (Schönberger, Humle, \& Teasdale, 2006). Schönberger et al. (2006) found that strong therapeutic rapport between patients with $\mathrm{TBI}$ and therapists significantly correlated to the reduction of depressive symptoms. A meta-analysis on patient satisfaction in the rehabilitation setting found that higher treatment satisfaction was associated with a higher level of compliance with treatment objectives and improved outcomes outside of the rehabilitation program (Keith, 1998). In a study on treatment satisfaction for chronic pain, Hirsh et al. (2005) found that patients were more likely to comply with treatment suggestions when they had a higher rate of satisfaction with their provider. We found that the treatment satisfaction after Internet-based cognitive rehabilitation was high, and associated with baseline level of self-management behavior, but not with level of cognitive impairment, age, level of education or time since onset of brain injury (Bergquist et al., 2010).

In this study we attempted to replicate our earlier findings on treatment satisfaction using a design comparing an active treatment condition with a wait list control. Consistent with our previous research, we hypothesized that our participants would report a high rate of satisfaction with our intervention, and that individuals with higher compensation use at baseline would also show a higher rate of satisfaction with treatment. We also predicted that greater satisfaction with treatment would be associated with an increased level of functioning (i.e., vocational status) and a decrease in activity limitations (i.e., as measured by family ratings on the
Neurobehavioral Functioning Inventory Memory and Depression subscales) over the course of treatment.

\section{METHOD}

\section{PARTICIPANTS}

A total of 15 adults ( 8 males and 7 females) out of 22 community dwelling adults with medically documented moderate to severe TBI signed consent forms and completed the study. Descriptive statistics showed no significant differences in demographic variables, living status, or memory performances between the 15 persons who completed the study and the seven who did not. Of those who dropped out, four persons were randomized to receive active treatment first and three were randomized to receive a waitlist condition first. Regardless of which treatment condition persons were randomized to, those who dropped out were not significantly different from those who completed the study on either of the demographic, injury related, psychiatric, or cognitive impairment variables ( $p>$.17). Descriptive statistics also showed no differences in demographic variables, living status or memory performance between those who received treatment first and those who were in the wait list condition first. The one exception to this was that participants randomized to the wait list condition first had significantly ( $p=0.03$ ) longer time from the time of injury to baseline evaluations as noted in Table 1.

Participants were recruited over an 18-month period from various local agencies that are part of local brain injury community committee and electronic postings through state brain injury associations in our region (lowa, Minnesota, and Wisconsin). See Tables 1 and 2 for complete demographic and injury related characteristics and cognitive functioning. 
Table 1. Descriptive Summaries for Demographic and Injury Variables

\begin{tabular}{|c|c|c|c|c|c|}
\hline Demographic Variables & $\begin{array}{c}\text { Total enrolled } \\
(\mathrm{n}=22) \\
\text { Median(range) }\end{array}$ & $\begin{array}{c}\begin{array}{c}\text { Non-completers } \\
(n=7)\end{array} \\
\text { (n) }\end{array}$ & $\begin{array}{c}\text { All completers } \\
(n=15)\end{array}$ & $\begin{array}{c}\text { Treatment } \\
\text { first } \\
(n=11)\end{array}$ & $\begin{array}{c}\text { Waitlist } \\
\text { first } \\
(n=11)\end{array}$ \\
\hline Age (in years) & $\begin{array}{c}42.0 \\
(21-63)\end{array}$ & $\begin{array}{c}30.0 \\
(21-52)\end{array}$ & $\begin{array}{c}43.0 \\
(22-63)\end{array}$ & $\begin{array}{c}41.0 \\
(21-63)\end{array}$ & $\begin{array}{c}43.0 \\
(30-58)\end{array}$ \\
\hline Education (in years) & $\begin{array}{c}14.8 \\
(12-20)\end{array}$ & $\begin{array}{c}14.5 \\
(12-20)\end{array}$ & $\begin{array}{c}15.00 \\
(12-18)\end{array}$ & $\begin{array}{c}16.0 \\
(12-20)\end{array}$ & $\begin{array}{c}14.5 \\
(12-18)\end{array}$ \\
\hline Gender (\% males) & 45.5 & 28.6 & 53.3 & 54.5 & 36.4 \\
\hline Ethnicity (\%) Caucasian & 100 & 100 & 100 & 100 & 100 \\
\hline $\begin{array}{l}\text { Marital Status (\%) } \\
\text { Single } \\
\text { Married or Living as } \\
\text { Married Separated or Other }\end{array}$ & $\begin{array}{r}41 \\
50 \\
9\end{array}$ & $\begin{array}{l}71.4^{\mathrm{a}} \\
14.3 \\
14.3\end{array}$ & $\begin{array}{r}26.7 \\
66.7 \\
6.7\end{array}$ & $\begin{array}{c}45.5 \\
45.5 \\
9.1\end{array}$ & $\begin{array}{r}36.4 \\
54.5 \\
9.1\end{array}$ \\
\hline $\begin{array}{l}\text { Time Since Injury to } \\
\text { Evaluation (months) }^{\star}\end{array}$ & $\begin{array}{c}68.5 \\
(13-457)\end{array}$ & $\begin{array}{c}70.5 \\
(16-318)\end{array}$ & $\begin{array}{c}56.5 \\
(13-457)\end{array}$ & $\begin{array}{c}40.0 \\
(13-145)\end{array}$ & $\begin{array}{c}169.0 \\
(16- \\
457)^{*}\end{array}$ \\
\hline $\begin{array}{l}\text { Type of Injury (\%) } \\
\text { TBI } \\
\text { CVA }\end{array}$ & $\begin{array}{c}94.0 \\
6.0\end{array}$ & $\begin{array}{l}83.3 \\
16.7\end{array}$ & $\begin{array}{c}100 \\
0\end{array}$ & $\begin{array}{l}87.5 \\
12.5\end{array}$ & $\begin{array}{c}100 \\
0\end{array}$ \\
\hline $\begin{array}{l}\text { Cause of Injury (\%) } \\
\text { MVA } \\
\text { Fall } \\
\text { Other }\end{array}$ & $\begin{array}{l}61.1 \\
22.2 \\
16.7\end{array}$ & $\begin{array}{l}66.7 \\
16.7 \\
16.7\end{array}$ & $\begin{array}{l}54.5 \\
27.3 \\
18.2\end{array}$ & $\begin{array}{l}66.7 \\
11.1 \\
22.2\end{array}$ & $\begin{array}{l}50.0 \\
37.5 \\
12.5\end{array}$ \\
\hline $\begin{array}{l}\text { Alcohol Use History } \\
\text { Alcohol Use (\% yes) } \\
\text { Alcohol Treatment }\end{array}$ & $\begin{array}{l}43.0 \\
30.8\end{array}$ & $\begin{array}{l}42.9 \\
20.0\end{array}$ & $\begin{array}{l}42.9 \\
37.5\end{array}$ & $\begin{array}{l}40.0 \\
25.0\end{array}$ & $\begin{array}{l}45.5 \\
40.0\end{array}$ \\
\hline $\begin{array}{l}\text { Psychiatric History (\% yes) } \\
\text { Diagnosed w/Depression } \\
\text { Diagnosed w/Anxiety } \\
\text { Currently seeing a Therapist }\end{array}$ & $\begin{array}{l}28.6 \\
61.9 \\
30.0\end{array}$ & $\begin{array}{l}42.9 \\
14.3 \\
28.6\end{array}$ & $\begin{array}{l}71.4 \\
35.7 \\
30.8\end{array}$ & $\begin{array}{l}50.0 \\
20.0 \\
18.2\end{array}$ & $\begin{array}{l}72.7 \\
36.4 \\
44.4\end{array}$ \\
\hline $\begin{array}{l}\text { Living Arrangement } \\
\text { Alone } \\
\text { With Family }\end{array}$ & $\begin{array}{l}14.3 \\
85.7\end{array}$ & $\begin{array}{l}28.6 \\
71.4\end{array}$ & $\begin{array}{c}7.1 \\
92.9\end{array}$ & $\begin{array}{r}0 \\
100\end{array}$ & $\begin{array}{l}27.3 \\
72.7\end{array}$ \\
\hline
\end{tabular}




\begin{tabular}{|l|c|c|c|c|c|}
\hline Vocational Independence & & & & & \\
Scale (\%) & 55.0 & 42.9 & 64.3 & 50.0 & 63.6 \\
Unemployed/Supported & 45.0 & 57.1 & 35.7 & 50.0 & 36.4 \\
Transitional/Employed & 16.7 & 0 & 21.4 & 11.1 & 20.0 \\
\hline Independent Living Scale (\%) & 83.3 & 100 & 78.6 & 88.9 & 80.0 \\
Dependent & & & & \\
Independent & & & & & \\
\hline
\end{tabular}

Note. "Those randomized to be waitlisted first had more months from injury to the baseline evaluation $(Z=-2.25, p=.03)$; the rest of the $p$ values $>.05$

Table 2. Descriptive Summary of Memory Performances and Compensation Use at Baseline

\begin{tabular}{|c|c|c|c|c|c|}
\hline & $\begin{array}{c}\text { Total enrolled } \\
(n=22) \\
\text { Median(range) }\end{array}$ & $\begin{array}{c}\text { Non-completers } \\
(n=7)\end{array}$ & $\begin{array}{c}\text { All completers } \\
(n=15)\end{array}$ & $\begin{array}{c}\text { Active } \\
\text { Treatment } \\
\text { first } \\
(n=11) \\
\end{array}$ & $\begin{array}{c}\text { Waitlist first } \\
(n=11)\end{array}$ \\
\hline \multicolumn{6}{|l|}{ Psychometrics } \\
\hline WRAT-3 (raw) & $\begin{array}{c}49.5 \\
(38-56)\end{array}$ & $\begin{array}{c}51.00 \\
(44-56)\end{array}$ & $\begin{array}{c}48.00 \\
(38-53)\end{array}$ & $\begin{array}{c}50.00 \\
(44-56)\end{array}$ & $\begin{array}{c}48.00 \\
(38-55)\end{array}$ \\
\hline RBANS Immediate Memory (SS) & $\begin{array}{c}84.0 \\
(49-129)\end{array}$ & $\begin{array}{c}87.00 \\
(53-129)\end{array}$ & $\begin{array}{c}83.00 \\
(49-109)\end{array}$ & $\begin{array}{c}76.00 \\
(53-109)\end{array}$ & $\begin{array}{c}85.00 \\
(49-129)\end{array}$ \\
\hline RBANS Delayed Memory (SS) & $\begin{array}{c}74.5 \\
(44-108)\end{array}$ & $\begin{array}{c}56.00 \\
(44-108)\end{array}$ & $\begin{array}{c}78.00 \\
(44-100)\end{array}$ & $\begin{array}{c}60.00 \\
(44-100)\end{array}$ & $\begin{array}{c}80.00 \\
(44-108)\end{array}$ \\
\hline RBANS List Learning I (z) & $\begin{array}{c}-1.4 \\
(-4.1-1.6)\end{array}$ & $\begin{array}{c}-0.6 \\
(-3.7-1.6)\end{array}$ & $\begin{array}{c}-1.7 \\
(-4.1-1.2)\end{array}$ & $\begin{array}{c}-1.8 \\
(-3.7-1.2)\end{array}$ & $\begin{array}{c}-1.1 \\
(-4.1-1.6)\end{array}$ \\
\hline RBANS Story memory I (z) & $\begin{array}{c}-.9 \\
(-3.1-1.5)\end{array}$ & $\begin{array}{c}-0.9 \\
(-3.1-1.5)\end{array}$ & $\begin{array}{c}-0.9 \\
(-3.1-1.0)\end{array}$ & $\begin{array}{c}-1.2 \\
(-3.1-1.0)\end{array}$ & $\begin{array}{c}-.6 \\
(-3.1-1.5)\end{array}$ \\
\hline RBANS List Recall (z) & $\begin{array}{c}-1.9 \\
(-4.2-1.9)\end{array}$ & $\begin{array}{c}-2.5 \\
(-4.2-1.9)\end{array}$ & $\begin{array}{c}-1.9 \\
(-4.2-.4)\end{array}$ & $\begin{array}{c}-2.5 \\
(-4.2-(-1.0))\end{array}$ & $\begin{array}{c}-1.7 \\
(-4.2-1.9)\end{array}$ \\
\hline RBANS List Recognition (z) & $\begin{array}{c}-2.0 \\
(-8.3-.5)\end{array}$ & $\begin{array}{c}-2.6 \\
(-8.3-.5)\end{array}$ & $\begin{array}{l}-1.5 \\
(-6.9)\end{array}$ & $\begin{array}{c}-4.0 \\
(-8.3-(-.5))\end{array}$ & $\begin{array}{c}-1.2 \\
(-4.5-.5)\end{array}$ \\
\hline RBANS Story Delayed Recall (z) & $\begin{array}{c}-1.3 \\
(-4.8-.9)\end{array}$ & $\begin{array}{c}-2.0 \\
(-4.8-.9)\end{array}$ & $\begin{array}{c}-1.1 \\
(-4.8-.6)\end{array}$ & $\begin{array}{c}-1.6 \\
(-4.8-.6)\end{array}$ & $\begin{array}{c}-1.1 \\
(-4.8-.9)\end{array}$ \\
\hline RBANS Figure Recall (z) & $\begin{array}{c}-1.7 \\
(-4.5-.5)\end{array}$ & $\begin{array}{c}-1.4 \\
(-4.2-(-.5))\end{array}$ & $\begin{array}{c}-1.7 \\
(-4.5-.5)\end{array}$ & $\begin{array}{c}-1.7 \\
(-4.5-.5)\end{array}$ & $\begin{array}{c}-1.1 \\
(-2.5-(-.5))\end{array}$ \\
\hline $\begin{array}{l}\text { CTQ4: Checks things off in } \\
\text { Calendar at least once a day (\% } \\
\text { of participants) } \\
\text { CTQ2: Makes Notes in Calendar } \\
\text { CTQ5: Calendar to Plan Ahead }\end{array}$ & $\begin{array}{l}45.5 \\
45.4\end{array}$ & $\begin{array}{l}57.2 \\
57.2\end{array}$ & $\begin{array}{l}41.0 \\
40.0\end{array}$ & $\begin{array}{l}27.3 \\
36.4\end{array}$ & $\begin{array}{l}63.7 \\
54.6\end{array}$ \\
\hline
\end{tabular}


Patients were included in the study if they: (a) had a medically documented history of moderate to severe TBI using the criteria described in an earlier study (Bergquist et al., 2009), (b) were 12-months post-TBI prior to study initiation, (c) had a sixth grade reading level on the Wide Range Achievement Test- $3^{\text {rd }}$ Edition (WRAT-3), (d) had evidence of memory impairment on psychometric testing, and (e) gave a self-report of memory complaints and associated reduction of participation in daily activities.

Participants who were eligible to enroll based on study inclusion criteria signed a consent form. The participants randomized to the Wait List (WL) condition were, on average, longer post-injury than those randomized to receive Active Treatment (AT) 'calendar training' first $(Z=$ $2.25, p=.03$ ). Each group in the study received both of the treatment conditions as part of the cross-over design (see Figure 1). Change scores after treatment were calculated after all participants completed both wait list and active treatment conditions, so that the original difference noted in months since injury was addressed by the study design itself. There were no other differences on demographic, injury, or memory impairment variables between the two groups. See Tables 1 and 2 for detailed descriptive summaries.

Of the 15 participants who completed the study, 53\% were male and $47 \%$ were female; $67 \%$ were married. They were on average 43 years old (range 22 to 63 years). Fifty five percent had at least some college education, and all had obtained a high school diploma. All participants were Caucasian. The vast majority (93\%) lived with one or more family members and most (78\%) were independent in basic activities of daily living (i.e., hygiene, grooming, and dressing). Sixty four percent were unemployed. The median length of time since injury was 56.5 months (range 13-457 months), with two participants recruited within one to two years post-injury, six participants within two to six years post-injury, and seven participants within 10 to 30 years post-injury. Twenty one percent reported some daily or more use of compensation strategies at baseline. Of those participants diagnosed with either depression or anxiety, $31 \%$ were currently seeing a therapist, $41 \%$ were taking antidepressants, and $13 \%$ were involved in both types of treatment.

\section{THERAPIST AND PSYCHOMETRIST TRAINING}

One therapist provided intervention for all persons involved in this study. The therapist was licensed with a master's degree in psychology with extensive clinical experience in cognitive rehabilitation. Several psychometrists conducted assessments for this study, all of whom had extensive training in the administration and scoring of psychological tests. Psychometrists were blinded as to the treatment condition (active treatment versus wait list) for each participant. Both the therapist and each of the psychometrists in this study worked under the supervision of the principal study investigator who is a board certified and licensed doctoral level neuropsychologist.

\section{PROCEDURE}

All participants in this IRB-approved experiment signed the written informed consent form prior to participation. After providing consent, participants were randomized to one of two cross-over study conditions: Active Treatment (AT) vs. Wait List (WL). Half of the randomized individuals received AT first, while the rest were placed in the WL condition. All treatment sessions were conducted via an instant messaging system previously described in detail in Bergquist et al., 2009.

All participants underwent a brief neuropsychological evaluation completed by a psychometrist under the supervision of a licensed clinical neuropsychologist to determine whether there was sufficient memory impairment required for participation eligibility. Those who were eligible to participate completed assessments at three time points: (1) at baseline prior to treatment participation, (2) following active treatment, and (3) after wait list condition.

The AT condition involved participating in 30 sessions of calendar use acquisition training based on the three-step procedure described by Sohlberg and Mateer

(1989). Calendar use skills were introduced and practiced in one-on-one sessions with a therapist via an IM system in order to develop more effective compensatory strategies to aid independent functioning in daily life.

Training sessions for using the IM system were completed during the initial session and training lasted no more than 2 hours. The training session consisted of two portions: one-on-one training with a therapist and a simulated session in which the participant logged onto the system and interacted with the therapist who was in a different location in the clinic via the IM system. The training session continued until participants exhibited the ability to fully log into the system without assistance. Participants were given a CD-ROM containing the program for this IM system and instructed on how to install it on their home computer.

The WL condition did not involve any treatment. At the end of the first study portion (i.e., AT or WL), all participants were re-administered the outcome measures. Following the second assessment, the WL condition started AT while those randomized to receive $A T$ first then received the $\mathrm{WL}$ condition. Following this second condition, participants were again given the outcome measures for a third and final time. Please refer to Figure 1 for a graphic representation of the study design. 


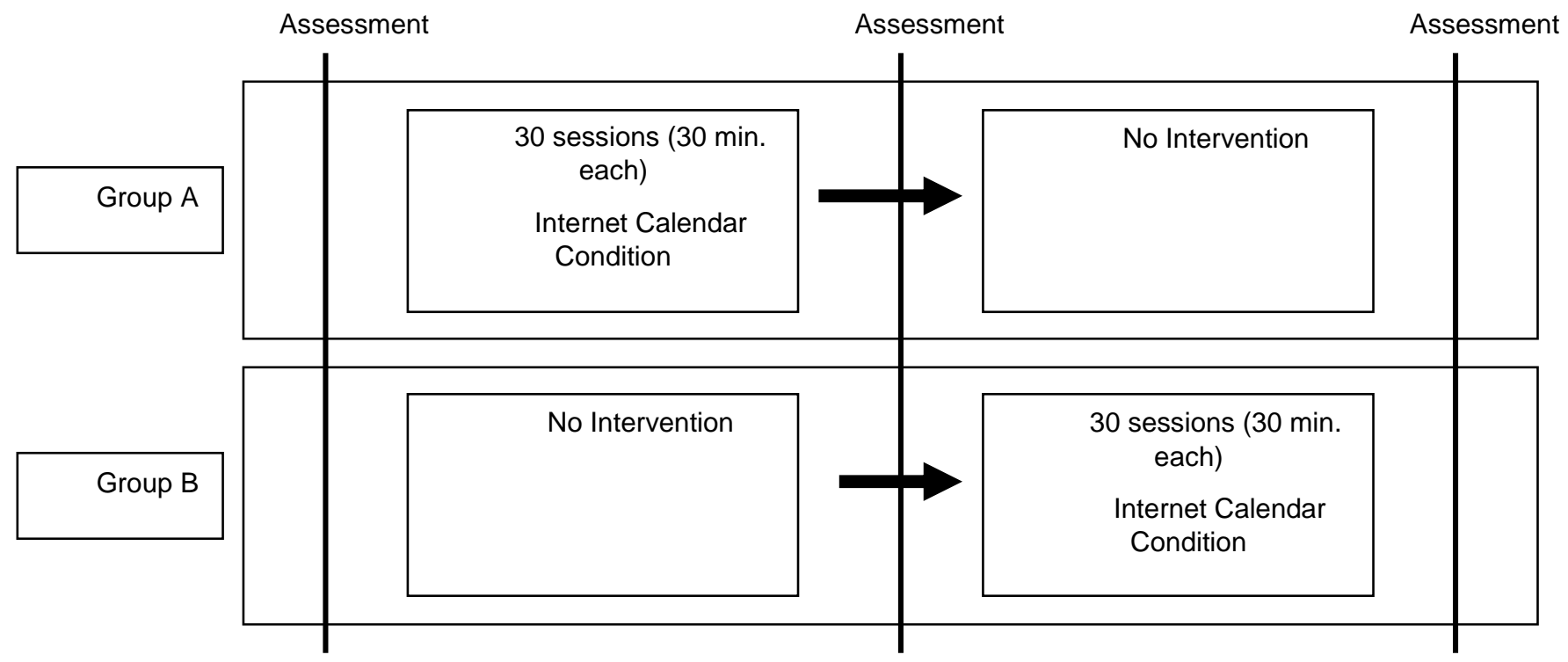

Figure 1. Graphic representation of the study design.

\section{OUTCOME MEASURES}

\section{COGNITIVE FUNCTIONING}

The Repeatable Battery of Neuropsychological Assessment (RBANS), is a brief psychometric battery that was administered to subjects to assess cognitive functioning across five domains: (1) Immediate memory, (2)

Visuospatial/Constructional, (3) Language, (4) Attention, and (5) Delayed Memory (Randolph, Tierney, Mohr, \& Chase, 1998).

\section{ACTIVITY LIMITATIONS}

The Neurobehavioral Functioning Inventory (NFI) measures neurologic disability, encompassing problems encountered during daily living, (e.g., the ability to remember certain tasks) as well as emotional and behavioral issues (e.g., feelings of irritability and shortened temper). One version is given to the person with the injury and a separate version is given to a family member or caretaker for comparison in the evaluation of health related quality of life (Marwitz, 2000).

\section{INDEPENDENT FUNCTIONING}

The Vocational Independence Scale (VIS) is a 3-point ordinal scale that quantifies an individual's degree of residential independence (Malec, Smigielski, DePompolo, \& Thompson, 1993). This scale assesses the participant's level of required supervision in daily life and includes 3 categories: (1) requires 24-hour supervision, (2) requires less than 24-hour supervision, or (3) is fully independent/no supervision required.

\section{COMPENSATION TECHNIQUES QUESTIONNAIRE (CTQ) (KUPACHI, 2002)}

The CTQ is a self-report measure of compensation strategies use (e.g., calendar, planners, cue cards) with each compensatory technique rated on a 7-point Likert scale. Selected questions were used from this instrument based upon our prior research (Bergquist et al., 2009).

\section{SATISFACTION WITH TREATMENT}

Four separate statements on participant satisfaction developed and reported in earlier research were used in this study (Bergquist et al., 2010). Agreement with each statement is rated on a 7-point Likert scale, with ratings of "1" Totally Disagree and " 7 " Totally Agree. The survey assesses satisfaction with the therapist and therapy received, emotional distress experienced during therapy, perception of the therapist as genuine and caring, as well as willingness to receive therapy again. Data was additionally 
dichotomized into Satisfied (ratings of 6 or 7 on each question with Question 2 reverse coded) vs. Not-Satisfied (ratings $<6$ or reverse coded on Question 2). See Table 3 for the Satisfaction Survey.

Table 3. Satisfaction Survey

\begin{tabular}{|l|}
\hline Satisfaction Survey \\
\hline 1. I am satisfied with the therapy I received. \\
\hline $\begin{array}{l}\text { 2. I experienced emotional distress during the therapy I } \\
\text { received. }\end{array}$ \\
\hline $\begin{array}{l}\text { 3. The therapist who provided me therapy genuinely } \\
\text { seemed to care about me. }\end{array}$ \\
\hline $\begin{array}{l}\text { 4. If I had the opportunity, I would want to receive therapy } \\
\text { again using e-mail. }\end{array}$ \\
\hline $\begin{array}{l}\text { Likert scale: 1, totally disagree; } 2, \text { disagree; } 3 \text {, disagree } \\
\text { somewhat; } 4 \text {, unsure; } 5 \text {, agree somewhat; } 6 \text {, agree; } 7, \\
\text { totally agree. }\end{array}$ \\
\hline
\end{tabular}

\section{STATISTICAL ANALYSES}

The Statistical Package for Social Sciences Version 15 (SPSS 15.0) was used for all statistical analysis. Nonparametric descriptive statistics (e.g., median, range, percentages) summarized demographic variables. Spearman rho correlations were used to examine the baseline associations between demographic variables, frequency of compensation use, activity limitations, and cognitive impairment. Wilcoxon rank sum test or Chi-square test (or Fisher's exact test) were utilized to examine the differences on demographic, memory, and primary outcome measures between those who completed the study and those who did not. Similar comparisons were made between the two randomized groups of study participants to assess whether the groups were comparable at baseline. For each participant, treatment changes from baseline to end of the AT condition were compared to treatment changes from baseline to post WL assessment. The Wilcoxon signed rank test was employed to compare these paired differences, in light of the small sample size and nonGaussian distribution of data.

As in previous studies (Bergquist et al., 2009; Bergquist et al., 2010), assessment of overall change from baseline to the last assessment, regardless of study condition, was done by calculating the difference between the baseline and final assessment, and completed as a post-hoc analysis. The Wilcoxon rank sum test examined the differences on satisfaction ratings between interim assessment (regardless of the study condition), final assessment after data were collapsed across groups, and after the active treatment condition. Two separate multivariate regressions further examined the confounding effects of psychosocial and injury variables on the relationship between activity limitations and satisfaction ratings, with activity limitations (i.e., ratings of mood and memory difficulties on the NFI) entered as dependent variables and satisfaction ratings, (i.e., age, education, and months since injury) entered as independent predictors. All tests were two sided and an alpha value of $<0.03$ was deemed statistically significant using a Bonferroni correction.

\section{RESULTS}

\section{SPECIFIC EFFECT COMPARISONS BETWEEN TREATMENTS (ACTIVE TREATMENT VERSUS WAIT LIST)}

The Wilcoxon signed rank test compared paired differences between the AT and WL groups on outcome measures, including participant and family ratings on the $\mathrm{NFI}$ and vocational status. One participant was missing data for family ratings of depression and memory on the NFI. There were no significant treatment differences on either patient or family-rated mood and memory scales on the NFI ( $p>$.09). Similarly, there were no significant differences between AT and WL conditions in vocational status $(z=-1.4$, $p>.16)$ and no differences on level of compensation strategy use ( $p>$.09). See Table 4 for a detailed descriptive summary of the neurobehavioral and vocational functioning measures.

There were also no significant differences in vocational status regardless of time of assessment $(z=-1.0, p=.32)$. Unlike previous studies, there were no significant differences between baseline and post-treatment assessments in the frequency of compensation strategy use (See Table 5 for all coefficients).

\section{SATISFACTION RATINGS}

Overall, the satisfaction of the participants was high. See Figure 2 for percentages for each of the four statements after active treatment condition. Note that given the wording of Question 2, it is reverse keyed, to be consistent with the other questions, so that a lower scores reflects greater satisfaction. Levels of treatment satisfaction were high (>87\%) and comparable to those in our previous study. 


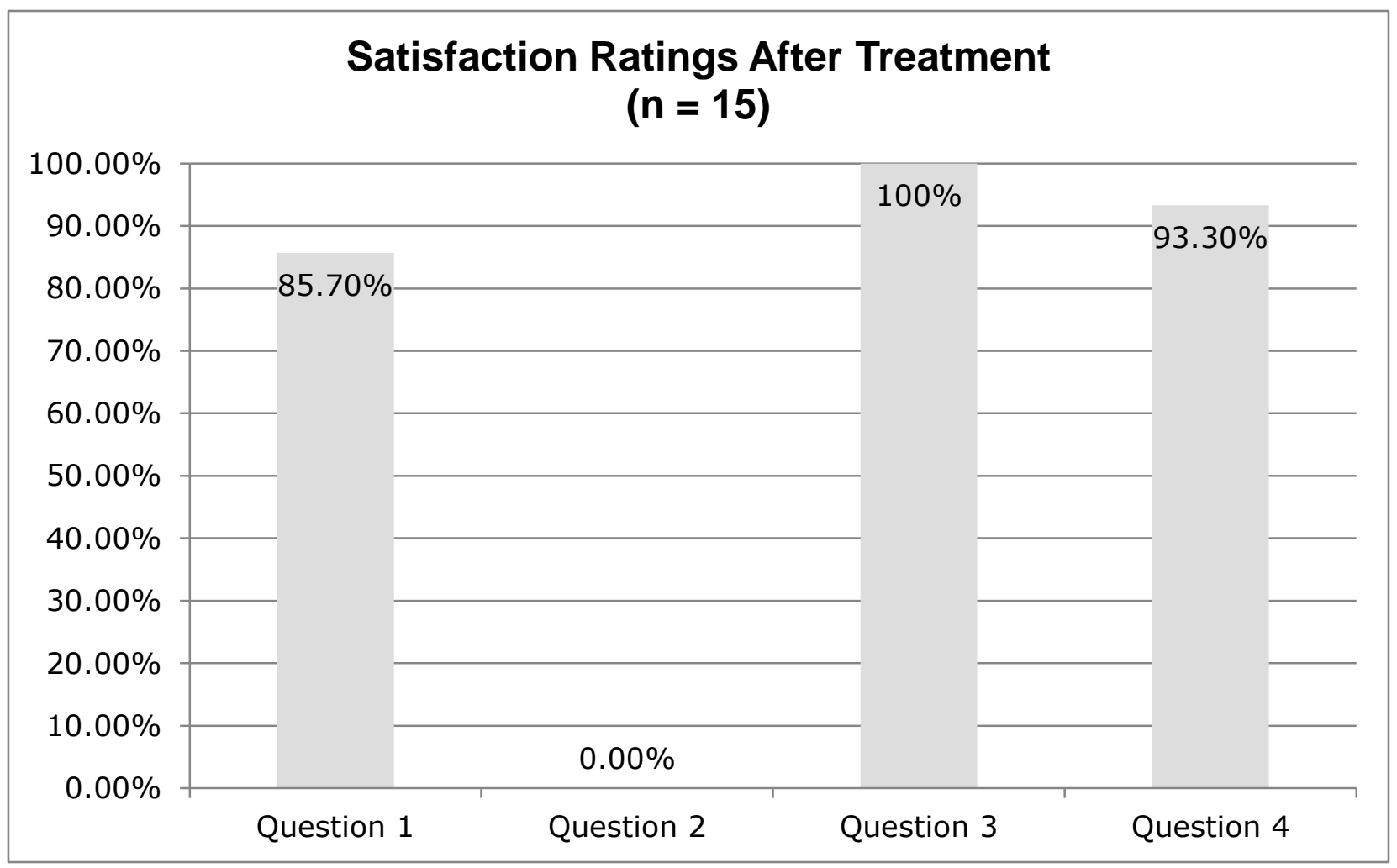

Note. Question 2 is reverse coded. See Table 3 for specific question wording on the Satisfaction Survey.

Figure 2. Percentages for each of the four statements after active treatment condition.

\section{SATISFACTION AND NEUROBEHAVIORAL FUNCTIONING}

Lower family ratings of mood difficulties on the NFI depression scale were associated with increased desire to receive therapy again (Question \#4), while lower family ratings of memory difficulties on the NFI memory scale after final assessment were associated with feeling that the therapist genuinely cared about the patient $(r=-.59, p=.03)$. There was no relationship between patient ratings of mood and memory problems and satisfaction.

To further explore these relationships and potential confounding effects of demographic and psychosocial variables on this relationship, we conducted two separate multivariate linear regressions for each of the dependent variables (i.e., family ratings of memory and mood on NFI memory and depression subscales) and demographic variables (i.e., age, education, months since injury, and satisfaction questions) entered as predictors. With alpha adjusted to 0.03 using a Bonferroni Correction, a multivariate regression analysis revealed that after adjusting for age, education, and months since injury, greater desire to participate in the same treatment again (Question \#4) uniquely accounted for $25 \%$ of additional variance in predicting lower family ratings of mood difficulties following final assessment $\left(R^{2}=0.46, \Delta R^{2}=0.25\right.$ ( $F$ change $(1,8)=7.12$, $p=0.03)$ ). Table 6 lists the coefficients and standard errors for the predictors of NFI Depression family ratings after final assessment. After adjusting for age, education, and months since injury, satisfaction with treatment (Question \#1) was no longer a significant predictor of family rated memory difficulties following final assessment $\left(R^{2}=0.24, \Delta R^{2}=0.15\right.$ ( $F$ change $(1,8)=1.75, p=0.23)$.

\section{SATISFACTION RATINGS AND VOCATIONAL STATUS}

As predicted, desire to receive therapy again using the same e-telehealth module (Question \#4) was positively correlated with vocational status after treatment $(r=.62$, $\mathrm{p}=.01$ ). Mann-Whitney analysis revealed significant difference in satisfaction based on employment status after treatment. Specifically, those who were employed after treatment were more likely to want the same intervention again than those who were unemployed $(z=-2.3, p=.02)$. Although not statistically significant, there was a trend for participants employed after therapy to view their relationship with their therapist more positively than did those who were unemployed $(Z=-1.76, p=.08)$. 
To further explore these relationships and potential confounding effects of demographic and psychosocial variables on patient satisfaction, we conducted a multivariate linear regression for the dependent variable (i.e., vocational status) with demographic variables (i.e., age, education, months since injury, and satisfaction questions) entered as predictors. With alpha adjusted to 0.03 using a Bonferroni Correction, analysis revealed that after adjusting for age, education, and months since injury, satisfaction with treatment (Question \#4) was no longer a significant predictor of vocational status after treatment, although there was a trend $\left(R^{2}=0.10, \Delta R^{2}=0.27\right.$ ( $F$ change $(1,9)=3.95, p=0.08)$ ).

\section{SATISFACTION RATINGS AND COMPENSATION STRATEGY USE}

Satisfaction ratings following treatment were not significantly correlated with compensation strategy use following treatment. Although not statistically significant, there was a trend between satisfaction ratings on Question \#3 (feeling as if the therapist genuinely cared for the patient) and greater frequency of making notes in the calendar (CTQ Question 2; $r=.51, p=.08$ ) and planning ahead in a calendar (CTQ Question 5; r=.52, $p=.07$ ) after final assessment.

Table 4. Treatment Effect: Active Treatment vs. Waitlist Condition ( $\mathrm{N}=14^{\mathrm{a}}$ )

\begin{tabular}{|c|c|c|c|}
\hline & $\begin{array}{c}\text { Active Treatment } \\
\text { Median (Range) or \% }\end{array}$ & $\begin{array}{c}\text { Waitlist Condition } \\
\text { Median (Range) or \% }\end{array}$ & $Z(p)$ \\
\hline NFI & & & \\
\hline Depression & & & \\
\hline $\begin{array}{l}\text { Patient Ratings }(n=15) \\
\text { Family Ratings }(n=14)\end{array}$ & $\begin{array}{l}2.00(-7.0-9.0) \\
-1.0(-8.0-27.0)\end{array}$ & $\begin{array}{l}2.0(-9.0-14.0) \\
1.5(-5.0-15.0)\end{array}$ & $\begin{array}{l}.56(.58) \\
-.56(.58)\end{array}$ \\
\hline $\begin{array}{l}\text { Memory } \\
\text { Patient Ratings ( } n=15) \\
\text { Family Ratings }(n=14)\end{array}$ & $\begin{array}{l}2.0(-10.0-13.0) \\
1.5(-19.0-24.0)\end{array}$ & $\begin{array}{c}3.0(-7.67-14) \\
-2.5(-23.0-15.0)\end{array}$ & $\begin{array}{l}-1.68(.09) \\
-.31(.76)\end{array}$ \\
\hline $\begin{array}{l}\text { VIS } \\
\text { Unemployed/Supported (\%) } \\
\text { Transitional/Employed (\%) }\end{array}$ & $\begin{array}{l}50 \\
50\end{array}$ & $\begin{array}{l}64.3 \\
35.7\end{array}$ & $-1.4(.16)$ \\
\hline $\begin{array}{l}\text { CTQ } \\
\text { Q2 (at least once a day) } \\
\text { Q4 } \\
\text { Q5 }\end{array}$ & $\begin{array}{l}50.0 \\
42.8 \\
21.4\end{array}$ & $\begin{array}{l}64.3 \\
50.0 \\
42.9\end{array}$ & $\begin{array}{l}-.92(.36) \\
-.21(.84) \\
-.15(, 88)\end{array}$ \\
\hline
\end{tabular}

Note. Median changes are reported for the NFI depression and Memory scales; percentages are reported for VIS

${ }^{a}$ One missing final assessment (NFI Questionnaire) from one family member, as such change scores for the NFI Family ratings from admission to discharge were only available for 14 out of the 15 patients. 
International Journal of Telerehabilitation • telerehab.pittedu

Table 5. Overall Treatment Effect: Baseline Assessment vs. Final Assessment

\begin{tabular}{|c|c|c|c|c|}
\hline & $\begin{array}{l}\text { Baseline Assessment } \\
\text { Median (Range) }\end{array}$ & $\begin{array}{l}\text { Final Assessment } \\
\text { Median (Range) }\end{array}$ & $\begin{array}{l}\text { Overall Change } \\
\text { Median (Range) }\end{array}$ & $Z(p)$ \\
\hline \multicolumn{5}{|l|}{$\mathrm{NFI}$} \\
\hline \multicolumn{5}{|l|}{ Depression } \\
\hline Patient Ratings & $32.5(15-54)$ & $32.5(17-47.67)$ & $2.0(-2.67-14.0)$ & $-1.65(.10)$ \\
\hline Family Ratings & $35.0(13-54)$ & $33(20-48)$ & $1.0(-8.0-27.0)$ & $-.67(.51)$ \\
\hline \multicolumn{5}{|l|}{ Memory } \\
\hline Patient Ratings & $51.0(27-87)$ & $49.0(20-75)$ & $3.0(-10.0-14.0)$ & $-2.11(.04)$ \\
\hline Family Ratings & $55.0(25-79)$ & $53.0(35-80)$ & $1.0(-18.0-24.0)$ & $-.04(.97)$ \\
\hline VIS & & & & $-1.0(.32)$ \\
\hline Unemployed/Supported(\%) & 64.3 & 57.1 & $7 \%$ & \\
\hline Transitional/Employed(\%) & 35.7 & 42.9 & $7 \%$ & \\
\hline \multicolumn{5}{|l|}{ CTQ } \\
\hline Q2 (at least once a day) & 40.0 & 57.1 & $17 \%$ & $-.27(.79)$ \\
\hline Q4 & 26.7 & 57.2 & $30.5 \%$ & $-.52(.61)$ \\
\hline Q5 & 13.4 & 42.9 & 29.5 & $-1.67(.09)$ \\
\hline
\end{tabular}

Table 6. Final Multivariate Regression Model for NFI Depression Family Ratings $\left(\mathrm{N}=14^{\mathrm{a}}\right)$

\begin{tabular}{|l|l|c|c|c|c|}
\hline & & \multicolumn{4}{|c|}{ NFI Patient Ratings } \\
\hline & & \multicolumn{4}{|c|}{ Depression } \\
\hline Block & Predictors & B & SE B & B & p \\
\hline 1 & Age & .40 & .20 & .53 & .08 \\
\hline & Education & .65 & 1.11 & .14 & .58 \\
\hline 2 & Months since injury & .02 & .01 & .29 & .18 \\
\hline
\end{tabular}

Block 1- $R^{2}=0.46(F(3,9)=2.6, p=0.12$

Block $2-R^{2}=0.71 \Delta R^{2}=0.25$ ( $F$ change $(1,8)=7.12, p=0.03$

${ }^{a}$ One missing final assessment (NFI Questionnaire) from one family member, as such change scores for the NFI Family ratings from admission to discharge were only available for 14 out of the 15 patients. 


\section{DISCUSSION}

We did not find any treatment effects in measures of activity or participation. In our previous study, we had similarly not found any group differences in outcome, but used a different control condition in which patients spent an equal amount of time with therapists, without receiving the treatment group intervention. Because the control condition involved equal time spent with a therapist, we proposed that there may have been added benefit from that interaction beyond the treatment alone which could have negated some of the group differences. As a follow-up from that study, and to provide a more robust comparison for the treatment condition, the current study compares a treatment group and a wait list condition. Even with this change, there are no differences between the treatment and control conditions. Given that a wait list control condition was used in this study, in which there was no contact with the therapist whatsoever, we are unable to speculate about the lack of treatment effects.

Despite the lack of any treatment effects in this study, there is still value to using the data collected on patient satisfaction with delivery of services to inform a telerehabilitation model, given the limited research on treatment satisfaction in this area (Cartwright, 2013; Whitten \& Love, 2005). Similar to our previous studies, we again found high treatment satisfaction suggesting once again that persons with acquired brain injury and memory impairments in general are highly satisfied with cognitive rehabilitation provided by a therapist over the Internet. Our hypothesis that participants with higher compensation use at baseline would report a higher rate of satisfaction with treatment was not supported. Our hypothesis that greater satisfaction with treatment would be associated with higher levels of functioning (i.e., vocational status) and lower levels of activity limitations (i.e., family ratings on the Neurobehavioral Functioning Inventory Memory and Depression subscales) was partially supported. After adjusting for age, education, and months since injury, greater desire to participate in the same treatment again was associated with lower family ratings of mood difficulties following treatment. Such a relationship was not found between family ratings of memory and satisfaction after adjusting for demographic variables (i.e., age, education and gender). Thus, while not associated with improvement over the course of treatment, there is at least partial support for an association between measures of activity and participation with treatment satisfaction.
It could be argued that without having demonstrated improvement in functioning after treatment in this study, reporting results of satisfaction with treatment has little, if any, meaning. In the field of telerehabilitation however, in which there continues to be limited evidence regarding treatment effectiveness and treatment satisfaction, these findings represent a modest but still valuable addition to the existing literature. Also, even though the lack of any change in treatment outcomes clearly questions the effectiveness of this treatment, the high level of satisfaction suggests that participants are potentially receiving some benefit from their involvement. If in contrast, the findings of this study showed improvement as the result of treatment, but was associated with low treatment satisfaction, it would be questionable if the results achieved would ever be repeated in a typical clinical practice setting. Consistent with this, a review of studies examining satisfaction with more traditional rehabilitation services found that improved satisfaction was associated with improved outcomes, improved compliance and a decreased rate of switching providers (Keith, 1998). Thus while not sufficient to achieve optimal treatment outcomes alone, patient satisfaction is arguably necessary for treatments to be consistently used by those whom it may help. Only with consistently high patient satisfaction will any rehabilitative treatment, no matter how effective, ultimately be able to achieve optimal treatment outcomes.

While our current study does not provide support for improved outcome after provision of cognitive rehabilitation provided using a telerehabilitation paradigm, it does show very high satisfaction for services provided in this manner and provides some preliminary information about which factors are associated with higher levels of satisfaction.

\section{ACKNOWLEGEMENT}

This publication was made possible by the Mayo Clinic CTSA through grant number UL1RR024150 from the National Center for Research Resources (NCRR), a component of the National Institutes of Health (NIH). 


\section{REFERENCES}

Bergquist, T., Gehl, C., Lepore, S., Holzworth, N., \& Beaulieu, W. (2008). Internet-based cognitive rehabilitation in individuals with acquired brain injury: A pilot feasibility study. Brain Injury, 22, 891897. doi: 903534285 [pii] 10.1080/02699050802405487

Bergquist, T., Gehl, C., Mandrekar, J., Lepore, S., Hanna, S., Osten, A., \& Beaulieu, W. (2009). The effect of Internet-based cognitive rehabilitation in persons with memory impairments after severe traumatic brain injury. Brain Injury, 23, 790-799. doi: 10.1080/02699050903196688

Bergquist, T. F., Thompson, K., Gehl, C., \& Munoz Pineda, J. (2010). Satisfaction ratings after receiving Internet-based cognitive rehabilitation in persons with memory impairments after severe acquired brain injury. Telemedicine Journal and e-Health, 16, 417-423. doi: 10.1089/tmj.2009.0118

Cartwright M. (2013). Effect of telehealth on quality of life and psychological outcomes over 12 months. British Medical Journal, 51, 346.

Egan, J., Worrall, L., \& Oxenham, D. (2005). An Internet training intervention for people with traumatic brain injury: Barriers and outcomes. Brain Injury, 19, 555-568.

Faul, M., Xu, L., Wald, M., \& Coronado, V. (2010). Traumatic brain injury in the United States: Emergency department visits, hospitalizations, and deaths, 2002-2006. Atlanta, GA: Centers for Disease Control and Prevention, National Center for Injury Prevention and Control.

Forducey, P. G., Glueckauf, R. L., Bergquist, T. F., Maheu, M. M., \& Yutsis, M. (2012). Telehealth for persons with severe functional disabilities and their caregivers: Facilitating self-care management in the home setting. Psychological Services, 9, 144162. doi: 2012-14616-003 [pii] 10.1037/a0028112

Goodman, N., Jette, A. M., Houlihan, B., \& Williams, S. (2008). Computer and Internet use by persons after traumatic spinal cord injury. Archives of Physical Medicine and Rehabilitation, 89, 1492-1498.

Hirsh, A. T., Atchison, J. W., Berger, J. J., Waxenberg, L. B., Lafayette-Lucey, A., Bulcourf, B. B., \& Robinson, M. E. (2005). Patient satisfaction with treatment for chronic pain: Predictors and relationship to compliance. Clinical Journal of Pain, 21, 302-310.

Johnstone, B., Nossaman, L. D., Schopp, L. H., Holmquist, L., \& Rupright, S. J. (2002). Distribution of services and supports for people with traumatic brain injury in rural and urban Missouri. Journal of Rural Health, 18, 109-117.

Keith, R. A. (1998). Patient satisfaction and rehabilitation services. Archives of Physical Medicine and Rehabilitation, 79, 1122-1128.
Kupachi, A. (2002). A long term use of compensation techniques following outpatient TBI rehabilitation. Minneapolis, MN: University of Minnesota.

Malec, J. F., Smigielski, J. S., DePompolo, R. W., \& Thompson, J. M. (1993). Outcome evaluation and prediction in a comprehensive-integrated postacute outpatient brain injury rehabilitation programme. Brain Injury, 7(1), 15-29.

Marwitz, J. (2000). The Neurobehavioral Functioning Inventory: The Center for Outcome Measurement in Brain Injury.

Ponsford, J. L., Downing, M. G., Olver, J., Ponsford, M., Acher, R., Carty, M., \& Spitz, G. (2014). Longitudinal follow-up of patients with traumatic brain injury: Outcome at two, five, and ten years post-injury. Journal of Neurotrauma, 31(1), 64-77. doi: 10.1089/neu.2013.2997

Randolph, C., Tierney, M. C., Mohr, E., \& Chase, T. N. (1998). The Repeatable Battery for the Assessment of Neuropsychological Status (RBANS): Preliminary clinical validity. Journal of Clinical and Experimental Neuropsychology, 20, 310-319. doi: 10.1076/jcen.20.3.310.823

Schopp, L. H., Johnstone, B. R., \& Merveille, O. C. (2000). Multidimensional telecare strategies for rural residents with brain injury. Journal of Telemedicine and Telecare, 6(Suppl 1), S146-S149.

Schönberger, M., Humle, F., \& Teasdale, T. W. (2006). Subjective outcome of brain injury rehabilitation in relation to the therapeutic working alliance, client compliance and awareness. Brain Injury, 20, 12711282.

Sohlberg, M. M., \& Mateer, C. A. (1989). Training use of compensatory memory books: A three stage behavioral approach. Journal of Clinical and Experimental Neuropsychology, 11, 871-891. doi: $10.1080 / 01688638908400941$

Vaccaro, M., Hart, T., Whyte, J., \& Buchhofer, R. (2007). Internet use and interest among individuals with traumatic brain injury: A consumer survey. Disability and Rehabilitation: Assistance and Technology, 2(2), 85-95.

Whitten P, Love B. (2005). Patient and provider satisfaction with the use of telemedicine: Overview and rationale for cautious enthusiasm. Journal of Postgraduate Medicine, 51, 294-300. 